\title{
Juvenile psoriatic arthritis and HLA antigens
}

\author{
M L Hamilton, D D Gladman, A Shore, R M Laxer, E D Silverman
}

\begin{abstract}
The clinical, laboratory, and radiological features, including histocompatibility typing, of 28 patients with juvenile psoriatic arthritis are reported. The most common presentation was that of psoriasis preceding or occurring simultaneously with arthritis. The most common course of juvenile psoriatic arthritis was to start as an oligoarthritis and progress, usually to polyarthritis. No patients with juvenile psoriatic arthritis had uveitis. Overall, most patients had a good outcome $(93 \%$ in functional class I and II), though $8 / 28$ (29\%) did require disease modifying drugs over a mean period of 8.8 years of follow up. The clinical features of these patients were very similar to those of a group of 158 adult patients with psoriatic arthritis with the same disease duration followed up in the clinic. Although there was an increased prevalence of $\mathrm{B17}$ in both juvenile and adult psoriatic arthritis, juvenile psoriatic arthritis showed increased prevalence of A2, whereas adult psoriatic arthritis showed increased prevalence of B27, Bw39, and Cw6. This HLA association differed from that reported in other forms of juvenile arthritis.
\end{abstract}

Juvenile psoriatic arthritis is defined as an inflammatory arthritis, usually seronegative, beginning before the age of 16 years, associated with psoriasis. ${ }^{1}$ According to this definition, psoriasis may either precede the onset of arthritis or occur within the subsequent 15 years. The entity has rarely been described despite the fact that the peak age of onset of psoriasis is reported to be between 5 and 15 years with $33 \%$ of all cases starting by age $15 .^{2}$ Indeed, fewer than 150 different subjects with this condition have ever been described.

Our objective was to define this entity further through detailed clinical, laboratory, and radiological evaluation. By presenting the largest immunogenetic analysis of juvenile psoriatic arthritis, we hoped to be able to identify further the genetic mechanisms thought to play a part in its aetiopathogenesis. When possible, the data were compared with those for a well defined cohort of adult patients with psoriatic arthritis, followed up in the same centre, who have been described previously. ${ }^{34}$

\section{Patients and methods}

Twenty eight patients entered the study in the psoriatic arthritis clinic and were seen at Women's College Hospital, Toronto. Pạtients were referred in the usual manner to the clinic, ${ }^{3}$ and from the Hospital for Sick Children by either rheumatologists or dermatologists.

Each patient was fully evaluated by the same doctor according to a standard protocol that included a complete history and physical examination.

Laboratory tests included complete blood count, erythrocyte sedimentation rate, liver and kidney function tests, serum protein electrophoresis, and determination of complement concentrations, rheumatoid factor, and antinuclear antibodies (using $\mathrm{HEp}_{2}$ substrate). All patients had complete HLA typing by the microcytotoxicity assay. ${ }^{4}$ Radiographs of hands, feet, spine, and pelvis were assessed. Statistical analysis was by $\chi^{2}$ and Fisher exact tests when indicated.

\section{Results}

CLINICAL FEATURES OF JUVENILE PSORIATIC

ARTHRITIS (table 1)

Sixteen female and 12 male subjects (F:M 1·3:1) with a mean age at the time of assessment of 19.4 (range 5-56) years were studied. The mean duration of arthritis at the time of assessment was $8 \cdot 8(0 \cdot 5-43)$ years. Fifteen $(54 \%)$ of patients were seen at the age of 16 or older. The mean age of onset of psoriasis was 8.75 (0-17) years, and of arthritis was 10.7 (1.4-16) years. There was no significant difference in the age of onset for female and male subjects. Psoriasis preceded the arthritis in half the patients (14), occurred simultaneously with arthritis ( \pm six months) in eight patients $(29 \%)$, and in six patients $(21 \%)$ the arthritis preceded psoriasis. A positive family history of psoriasis was present in 18 of $26(69 \%)$ patients, but a positive family history of psoriatic arthritis was much less common $(6 / 26(23 \%))$. Two patients were adopted and did not know their family history.

Table 1 Clinical features of 28 patients with juvenile psoriatic arthritis. Number (\%) of patients is given

\begin{tabular}{lc}
\hline Number of female subjects & 16 \\
Number of male subjects & 12 \\
Mean age at assessment (years) & $19 \cdot 4(5-56)$ \\
Duration of arthritis (years) & $8 \cdot 8(0 \cdot 5-43)$ \\
Mean age at onset of psoriasis (years) & $8 \cdot 75(0-17)$ \\
Mean age at onset of arthritis (years) & $10 \cdot 7(1 \cdot 4-16)$ \\
Onset of psoriasis before arthritis & $14(50)$ \\
Onset of arthritis before psoriasis & $6(21)$ \\
Simultaneous onset \pm 6 months & $8(29)$ \\
Family history of psoriasis & $18(69)^{*}$ \\
Family history of psoriatic arthritis & $6(23)^{*}$ \\
Uveitis & 0 \\
Psoriasis pattern & $26(93)$ \\
Vulgaris & $2(7)$ \\
Guttate & $20(71)$ \\
Nail disease &
\end{tabular}

*Two patients did not know their family history. 
Six patients (21\%) had extra-articular features-five (18\%) had tendinitis and one (4\%) had mouth ulcers. Twenty six (93\%) had psoriasis vulgaris and two (7\%) had guttate psoriasis. Nail lesions were present in $20(71 \%)$ patients and were more common in male than female subjects $(83 \% v 62.5 \%)$. None of the patients had eye disease.

\section{PATTERN OF ARTICULAR DISEASE}

The mode of onset was acute in eight patients (29\%), but most had a gradual onset of joint disease. The most common presentation was oligoarticular disease with or without back involvement in 12 patients $(43 \%)$. The second most common pattern of presentation was distal only-that is, distal interphalangeal and proximal interphalangeal joints (table 2).

Skin and joints flared together in a minority of patients $(8 / 28(29 \%))$. Distal interphalangeal joint disease occurred in 16 patients $(57 \%)$, nine of whom had associated dactylitis. The most common course of arthritis was an asymmetric polyarticular disease $(12 / 28(43 \%))$. No comparison could be made between the groups with psoriasis vulgaris and guttate psoriasis as only two patients had guttate psoriasis. Both were female, one had had juvenile psoriatic arthritis for seven years, whereas diagnosis of juvenile psoriatic arthritis in the other had only been made six months before the study, and no comment can be made about the course of her disease.

\section{LABORATORY DATA}

Laboratory investigations (table 3) were essentially normal. There was no correlation between haemoglobin concentrations or erythrocyte sedimentation rate and the activity of arthritis. Two patients had a positive rheumatoid factor in low titres $-1 / 80$ and 1/320. These patients were seen as adults for the first time. Two patients had positive antinuclear antibody tests (1/160 and $1 / 80$, homogeneous pattern). Table 4 shows the results of HLA typing, which indicated an increased prevalence of HLA-A2 and B17. The increased prevalence of DR7

Table 2 Clinical course of juvenile psoriatic arthritis. Number (\%) of patients is given

\begin{tabular}{lc}
\hline Pattern at onset & $11(39)$ \\
Oligoarthritis & $1(3 \cdot 5)$ \\
Oligoarthritis and back & $5(18)$ \\
Polyarthritis & $2(7)$ \\
Polyarthritis and back & $7(25)$ \\
Distal only & $1(3 \cdot 5)$ \\
Back only & $1(3 \cdot 5)$ \\
Distal and back & $9(32)$ \\
Course of articular disease & $1(3 \cdot 5)$ \\
Oligoarthritis & $8(29)$ \\
Oligoarthritis and back & $4(14)$ \\
Polyarthritis & $3(11)$ \\
Polyarthritis and back & $1(3 \cdot 5)$ \\
Distal only & $2(7)$ \\
Back only & $11(39)$ \\
Distal and back & $16(57)$ \\
Dactylitis & $8(29)$ \\
Distal interphalangeal joint disease & $10(36)$ \\
Simultaneeous flare & $16(57)$ \\
Functional class & $1(3 \cdot 5)$ \\
Grade I & $1(3 \cdot 5)$ \\
Grade II & $8(29)$ \\
Grade III &
\end{tabular}

Table 3 Laboratory and radiologic features of juvenile psoriatic arthritis. Number (\%) of patients is given

\begin{tabular}{ll}
\hline Rheumatoid factor titre $(>1 / 80)$ & $2(7)$ \\
Antinuclear antibody titre $(>1 / 40)$ & $2(7)$ \\
Erosive changes on radiographs & $10 / 25(40)$ \\
Stage 4 disease & $3 / 25(12)$ \\
More than five joints at stage 4 & 0 \\
Periostitis & $2 / 25(8)$ \\
Sacroiliitis & $8 / 20(40)$ \\
Sacroiliitis of >grade 2 & $6 / 20(30)$ \\
Symptomatic sacroiliitis & $2 / 8(25)$ \\
Syndesmophytes & $1 / 4(25)$ \\
Classic & $1 / 4(25)$ \\
Paramarginal & \\
\hline
\end{tabular}

Table 4 HLA typing

\begin{tabular}{|c|c|c|c|c|c|}
\hline $\begin{array}{l}H L A \\
y p e\end{array}$ & $\begin{array}{l}\text { Patients* } \\
(n=28)\end{array}$ & $\begin{array}{l}\text { Controls* } \\
(n=276)\end{array}$ & $x^{2}$ & $p$ Value & $R R t$ \\
\hline $\begin{array}{l}\text { A2 } \\
\text { B7 } \\
\text { B8 } \\
\text { B17 } \\
\text { B27 } \\
\text { B44 } \\
\text { DR4 } \\
\text { DR5 } \\
\text { DR7 }\end{array}$ & $\begin{array}{r}20(71) \\
7(25) \\
4(14) \\
9(32) \\
3(11) \\
7(25) \\
6(21) \\
1(4) \\
14(50)\end{array}$ & $\begin{array}{l}125(45) \\
62(22) \\
70(25) \\
21(8) \\
21(8) \\
67(24) \\
86(31) \\
46(17) \\
86(31)\end{array}$ & $\begin{array}{c}5.95 \\
0.00 \\
1.12 \\
14.5 \\
0.04 \\
0.03 \\
0.72 \\
2.4 \\
3.27\end{array}$ & $\begin{array}{l}<0 \cdot 05 \\
\text { NS } \\
\text { NS } \\
<0 \cdot 001 \\
\text { NS } \\
\text { NS } \\
\text { NS } \\
\text { NS } \\
\text { NS }\end{array}$ & $\begin{array}{l}3.02 \\
1.15 \\
0.48 \\
5.75 \\
1.4 \\
1.02 \\
0.6 \\
0 \cdot 18 \\
2 \cdot 48\end{array}$ \\
\hline
\end{tabular}

*Number (\%) of patients is given.

$+R R=$ relative risk.

(50\%) compared with the expected prevalence of $31 \%$ was not statistically significant.

RADIOLOGICAL MANIFESTATIONS (table 3)

Radiographs showed the presence of erosive disease in $10 / 25(40 \%)$ patients with stage 4 changes_of ankylosis or joint destruction in $3 / 25$ (12\%). Sacroiliitis of grade 2 or more was found in 6/20 (30\%). One patient had classic syndesmophytes and one other had paramarginal syndesmophytes. Only $2 / 8(25 \%)$ of all patients with radiological sacroiliitis were symptomatic and none of them was found to be HLA-B27 positive. Periostitis was seen in only $2 / 25(8 \%)$ patients.

PROGNOSIS OF JUVENILE PSORIATIC ARTHRITIS At the time of assessment $26(93 \%)$ patients were in functional classes I or II. Only two were severely restricted, both of them girls. Interestingly, both had had a simultaneous onset of psoriasis and arthritis in their mid-teens (14 and 15). Both had had a polyarticular onset with

Table 5 Subsets based on severity of arthritis. Number (\%) of patients is given

\begin{tabular}{llll}
\hline & $\begin{array}{l}\text { Mild } \\
\text { arthritis } \\
(n=20)\end{array}$ & $\begin{array}{l}\text { Severe } \\
\text { arthritis } \\
(n=8)\end{array}$ & $p$ Value \\
\hline $\begin{array}{l}\text { Polyarticular arthritis } \\
\text { pattern at onset }\end{array}$ & $1(5)$ & $6(75)$ & $<0 \cdot 03$ \\
$\begin{array}{l}\text { Dactylitis } \\
\text { Nail disease }\end{array}$ & $9(45)$ & $2(25)$ & NS \\
HLA type: & $13(65)$ & $7(88)$ & NS \\
A2 & $14(70)$ & $6(75)$ & NS \\
A11 & $1(5)$ & $3(38)$ & $<0 \cdot 055$ \\
B7 & $3(15)$ & $4(50)$ & $<0 \cdot 06$ \\
B27 & $3(15)$ & 0 & NS \\
B13 & $1(5)$ & $2(25)$ & NS \\
DR7 & $9(45)$ & $5(63)$ & NS \\
\hline
\end{tabular}

*Based on the need for second line agents-for example, methotrexate, due to severity of arthritis. 
Table 6 Comparison of juvenile and adult psoriatic arthritis (same clinic). Number (\%) of patients is given

\begin{tabular}{|c|c|c|}
\hline & \multicolumn{2}{|c|}{ Psoriatic arthritis } \\
\hline & $\begin{array}{l}\text { fuvenile } \\
(n=28)\end{array}$ & $\begin{array}{l}\text { Adult } \\
(n=158)\end{array}$ \\
\hline $\begin{array}{l}\text { Women:men } \\
\text { Family history of psoriasis/psoriatic arthritis* } \\
\text { Psoriasis pattern } \\
\text { Vulgaris } \\
\text { Guttate } \\
\text { Nail lesions } \\
\text { Most common presentation } \\
\text { Most common pattern } \\
\text { Skin and joints flare simultaneously } \\
\text { Uveitis } \\
\text { Dactylitis } \\
\text { Distal interphalangeal joint disease } \\
\text { Erosive } x \text { rays } \\
\text { Stage } 4 x \text { rays } \\
\text { Sacroiliitis of >grade } 2 \\
\text { HLA typing significantly different from controls }\end{array}$ & $\begin{array}{l}16: 12(1 \cdot 33) \\
19 / 26(73) \\
26(93) \\
2(7) \\
20(71) \\
\text { Oligoarthritis } \\
12(43) \\
\text { Polyarthritis } \\
12(43) \\
8(29) \\
0 \\
11(39) \\
16(57) \\
10 / 25(40) \\
3 / 25(12) \\
6 / 20(30) \\
\text { A2, B17 }\end{array}$ & $\begin{array}{l}84: 74(1 \cdot 13) \\
64(41) \\
147(93) \\
11(7) \\
131(83) \\
\text { Polyarthritis } \\
76(48) \\
\text { Polyarthritis } \\
100(63) \\
55(35) \\
11(7) \\
52(33) \\
85(54) \\
106(67) \\
47(30) \\
43(27) \\
\text { B17, B27, Bw39, Cw6 }\end{array}$ \\
\hline
\end{tabular}

Two patients did not know their family history.

axial involvement. Neither had extra-articular features, neither was HLA-DR4 positive, and neither had positive rheumatoid factor or antinuclear antibody tests.

Twenty two of the 28 patients had been followed up for at least two years. Eleven of these 22 patients had polyarthritis, affecting the back in some. Most of these patients (21/22 $(95 \%))$ were in functional class I or II. Seven of the 22 patients (32\%) did require second line agents for their arthritis, however. None had received methotrexate for the skin disease alone.

Some differences were noted when patients requiring remittive treatment for control of their arthritis were compared with those with milder disease (table 5). The patients with more severe arthritis (based on the need for second line agents-for example, gold, methotrexate, owing to persistent inflammatory activity of arthritis or the presence of erosive disease) were more likely to have a polyarticular onset $(6 / 8$ $(75 \%) v 1 / 20(5 \%))(\mathrm{p}<0.001)$. They were also more likely to have nail disease $(7 / 8(88 \%) v$ $13 / 20(65 \%))$. HLA types A11 and B7 were more common in the severe subset, though the difference did not reach statistical significance. The prevalence of HLA-DR4 was similar in both groups.

\section{JUVENILE VERSUS ADULT PSORIATIC}

ARTHRITIS IN THE SAME CLINIC (table 6)

Both adult and juvenile psoriatic arthritis had a similar sex distribution. The most common presentation in juvenile psoriatic arthritis was oligoarthritis $(12 / 28(43 \%))$, whereas in adult psoriatic arthritis it tended to be polyarthritis $(76 / 158(48 \%))$. Both juvenile $(12 / 28(43 \%))$ and adult patients $(100 / 158(63 \%))$ followed a similar course of disease; both were most likely to develop polyarthritis. Skin and joints flared simultaneously in a similar proportion of people $(8 / 28(29 \%) v 55 / 158(35 \%))$. The prevalence of distal interphalangeal joint disease $(16 / 28(57 \%)$ $v 85 / 158(54 \%))$ and dactylitis $(11 / 28(39 \%) v$ $52 / 158(33 \%)$ ) was essentially the same. The prevalence of sacroiliitis of more than grade 2 was also the same $(6 / 20(30 \%) v 43 / 158(27 \%))$.
Thus during a similar follow up period $(8 \cdot 8$ years $v 9$ years), the clinical features were remarkably similar. Although both juvenile and adult psoriatic arthritis were associated with $\mathrm{B} 17$, the prevalence of $\mathrm{A} 2$ was increased in juvenile psoriatic arthritis, whereas B27, Bw39, and Cw6 were increased in adult psoriatic arthritis.

\section{Discussion}

Psoriasis has been found to affect between 1 and 2\% of North American and European white subjects. ${ }^{5}$ Juvenile psoriatic arthritis, however, originally described by Ansell and Bywaters in $1962,{ }^{1}$ is considered to be fairly uncommon. Its prevalence has been quoted at 3/100 000, much rarer than juvenile rheumatoid arthritis $(66 / 100000)$ or juvenile ankylosing spondylitis $(>30 / 100000) .^{6}$ Two studies have outlined the difficulties encountered in the diagnosis of juvenile psoriatic arthritis, ${ }^{78}$ which may partially explain the paucity of published series. ${ }^{7-10}$

Juvenile psoriatic arthritis has been described as an asymmetric polyarthritis affecting upper and lower limbs, commonly associated with dactylitis. Various differences have been noted between juvenile psoriatic arthritis and the currently recognised patterns of juvenile rheumatoid arthritis. The mode of onset of juvenile psoriatic arthritis is predominantly oligoarticular yet progression to polyarthritis is striking with $82 \%$ of oligoarticular onset arthritis proceeding to polyarthritis compared with only $30-40 \%$ of children in a corresponding group with pauciarticular juvenile arthritis. One fifth of children had a swollen tendon sheath of a single finger or toe, associated with synovitis of all three finger or two toe joints, compared with the flexor tenosynovitis of juvenile rheumatoid arthritis, which tends to have just proximal interphalangeal joint swelling. ${ }^{7}$

In one study chronic iridocyclitis was seen less commonly-11\% of a group with pauciarticular arthritis developed eye disease ${ }^{7}$ compared with the expected incidence of $22-30 \%$ in pauciarticular juvenile rheumatoid arthritis. Another study, however, found chronic iridocyclitis in $22 \%$ of their 24 patients with definite juvenile psoriatic arthritis. ${ }^{11}$ As in juvenile rheumatoid arthritis, chronic iridocyclitis in juvenile psoriatic arthritis was associated with a positive antinuclear antibody test. It has been suggested that antinuclear antibodies, even in the absence of chronic iridocyclitis, imply a poor functional outcome. ${ }^{7}$

In our group of 28 patients there was a slight female predominance $(1 \cdot 33)$ as has been described in adult psoriatic arthritis ${ }^{3}$ (table 6). The most common presentation was that of psoriasis preceding or occurring simultaneously with arthritis, as has been reported in adult juvenile psoriatic arthritis. As noted in other studies the most common type of onset was oligoarthritis with most patients eventually developing an asymmetric polyarthritis.

Simultaneous flare of skin and joint disease was seen in $8 / 28$ (29\%) patients, comparable with that seen in the adult population $(55 / 158$ $(35 \%)) .^{3}$ Overall, the disease seemed rather 
benign (26/28 (93\%) in functional classes I and II), as noted in previous studies. This must be interpreted with some caution, as $8 / 28(29 \%)$ of patients were thought to require slow acting drugs-for example, gold, methotrexate, at some time during their disease. Nevertheless, the overall disease seems to be more benign than adult psoriatic arthritis. ${ }^{3}$ Uveitis did not occur in any of our patients.

Patients with more severe juvenile psoriatic arthritis were more likely to have a polyarticular onset $(5 / 8(63 \%) v 1 / 20(5 \%))$ with more common nail disease $(7 / 8(88 \%) v 13 / 20(65 \%))$. Dactylitis appeared slightly more often in milder arthritis. In our patient sample a positive antinuclear antibody test was not found more often with more severe arthritis, nor was the HLA-DR4 a marker of more severe disease.

HLA typing showed an increased prevalence of HLA-A2 and B17 and a possible increase in DR7. This differed from the associations found in the cohort of patients with adult psoriatic arthritis from the same clinic, ${ }^{4}$ where an increased prevalence of $\mathrm{B} 17, \mathrm{~B} 27, \mathrm{Bw} 39$, and Cw6 was seen with no association with the DR locus. Others, however, have reported the prevalence of DR7 to be greater in adult psoriatic arthritis. ${ }^{12}$

Immunogenetics of subsets of juvenile rheumatoid arthritis have been studied extensively and recently reviewed. ${ }^{13}$ Early onset pauciarticular disease was associated with HLADRw8, DR5, and A2, whereas polyarticular onset rheumatoid factor positive juvenile rheumatoid arthritis was associated with HLA-DR1 and DR4. A rheumatoid factor negative subset of the polyarticular group is possibly associated with DRw8 and DR4. Systemic onset juvenile rheumatoid arthritis is in itself probably a heterogeneous group, and various HLA associations based on small patient groups have been postulated. There does seem to be a moderate association with DR4. ${ }^{14}$ Despite the fact that $22 / 28$ of our patients had a pauciarticular onset, HLA-DR5 was notably rare (1/28), indicating that juvenile psoriatic arthritis and pauciarticular juvenile rheumatoid arthritis are distinct entities. Contrary to a previous report, ${ }^{15}$ HLAB8 was not found to be a marker of more severe disease, nor was HLA-B17 a marker for more benign disease.

Owing to the broad definition of juvenile psoriatic arthritis, the referral source of these patients may greatly influence the patients encountered. We believe our patient group is more reflective of most patients with juvenile psoriatic arthritis than some previous series because our patients were referred by both dermatologists and rheumatologists rather than just from a tertiary national hospital for children with severe arthritis.

In conclusion, juvenile psoriatic arthritis seems to be an entity separate from other types of juvenile rheumatoid arthritis as well adult psoriatic arthritis, not only clinically but also on the basis of immunogenetic analysis.

1 Ansell B M, Bywaters E G L. Diagnosis of "probable" Still's disease and its outcome. Ann Rheum Dis 1962; 21: 253-61. disease and its outcome. Ann Rheum Dis 1962; 21 : 253-61. $139-45$.

3 Gladman D D, Shuckett R, Russell M L, Thorne J C, Schachter R K. Psoriatic arthritis (PsA)-an analysis of 220 patients. $Q \mathcal{F}$ Med 1987; 238: 127-41

4 Gladman D D, Anhorn K A B, Schachter R K, Mervart H. HLA antigens in psoriatic arthritis. $\mathcal{F}$ Rheumatol 1986; 13: 586-91.

5 Baker $\mathrm{H}$. Epidemiological aspects of psoriasis and arthritis. Br $f$ Dermatol 1966; 78: 249-61.

6 Bywaters E G L. Diagnostic criteria for Still's disease. In: Bennett R H, Wood R H N, eds. Population studies of the rheumatic diseases. New York: Excerpta Medica, 1968.

7 Shore A, Ansell B M. Juvenile psoriatic arthritis-ANA

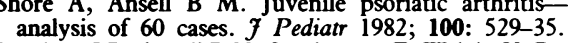

8 Lambert J R, Ansell B M, Stephenson E, Wright V. Psoriatic arthritis in childhood. Clin Rheum Dis 1976; 2: 339-52. Calabro J J. Psoriatic arthritis in children. Arthritis Rheum 1977; 20 (suppl 2): 415-6.

10 Sills E M. Psoriatic arthritis in childhood. Fohns Hopkins Medical foumal 1980; 146: 49-53.

11 Southwood T R, Petty R E, Malleson P N, et al. Psoriatic arthritis in children. Arthritis Rheum 1989; 32: 1007-13.

12 McKendry R J R, Sengar D P S, Des Groseilliers J P, Dunne $\mathrm{J}$ V. Frequency of HLA antigens in patients with psoriasis
or psoriatic arthritis. Can Med Assoc $\mathcal{F} 1984 ; 130: 411-5$.

13 Albert E, Ansell B M. Immunogenetics of juvenile chronic arthritis. Scand f Rheumatol [Suppl] 1987; 66: 85-91.

14 Hall P J, Berman S J, Laurent M R, et al. Genetic susceptibility to early onset pauciarticular JCA. A study of HLA and complement markers in 158 British subjects. Ann Rheum Dis 1986; 45: 464-74.

15 Shore A, Gladman D, Keystone E, Clemens L, Ansell B M Subgroups of juvenile psoriatic arthritis [Abstract]. Annals of the Royal College of Physicians and Surgeons Canada 1981; 14: 2336 . 